\title{
The levels of Acrylamide in food items and the effect of re-heating of fried and baked foods on Acrylamide levels
}

\section{Isam. M Jawad, Tawfic Arafat and Marwan Al Muwalla}

Faculty of Pharmacy and Medical Sciences. University of Petra, Amman. P.o Box: 961343, Jordan.

Correspondence Author: Isam. M. Jawad, Faculty of Pharmacy and Medical Sciences. University of Petra, Amman. P.0 Box: 961343 , Jordan.

E-mail: imjisam@yahoo.com

Received date: 23 July 2018, Accepted date: 15 November 2018, Online date: 25 November 2018

Copyright: (C) 2018 I. M. Jawad et al., This is an open-access article distributed under the terms of the Creative Commons Attribution License, which permits unrestricted use, distribution, and reproduction in any medium, provided the original author and source are credited.

\begin{abstract}
Background: Acrylamide is a toxic compound, probable carcinogen and mutagen for humans. Research shows that the compound is created in significant quantities when the food is prepared at high temperatures such as frying, baking and in some cases when using dry heat. To be specific, the Millard reaction between amino acids and reducing sugars that occurs during the heat treatment of food leads to the creation of Acrylamide. The purpose of this study is to determine the Acrylamide levels in selected food items specifically in those items which are rich in carbohydrates and to study the effects of reheating food on the levels of Acrylamide. An investigation was carried out on samples of processed food such as fried potatoes as well as different types of breads consumed across Jordan using Liquid Chromatography (LC) Tandem Mass Spectrometry (MS) technique to determine the level of Acrylamide before and after the heat treatment. Significant amounts of Acrylamide were found in different samples of the processed food. The effect of reheating processes had directly impacted the levels of Acrylamide in fried potatoes, baked food as well as in other samples too.
\end{abstract}

Key words: Acrylamide, frying, Reheating, Maillard reaction, Carcinogen, Carbohydrates,

\section{INTRODUCTION}

Acrylamide is produced in significant quantities when the food is prepared using high temperature such as frying, baking and even drying. Such high temperature and the presence of carbohydrates and protein lead to the formation of this compound under Maillard reaction between amino acid 'asparagines' and reducing sugars such as 'glucose' [1-3]. Acrylamide has been classified as group 2A carcinogen by International agency for research on cancer [3-5]. It has been proven from animal experiments that Acrylamide is a toxic compound and probably a carcinogen and mutagen for human beings. The FAO/WHO [5] consultation acknowledged the potential link between Acrylamide and carbohydrate-rich foods that are over-cooked for long periods of time under very high temperatures [6].

In Jordanian diet, carbohydrate-rich food forms the main constituent as reported by Food and Agriculture Organization of the United Nations (FAO) in the year 2011.Typically, this includes different types of breads prepared locally as well as others such as pastry, rice, sweets (kunafa) etc. The preparation of such food items involves high temperature cooking e.g. baking, roasting, and frying. Therefore, traditional carbohydrate-rich Jordanian foods may represent high-risk levels of Acrylamide when exposed to excessive heating processes.

The Acrylamide levels in food have been documented in a number of countries. In 2002, Sweden was one of the first few countries to monitor the level of Acrylamide in food. The intake of Acrylamide is approximately 35ug per person per day [7-9]. It is not practical to extrapolate the results of dietary exposure from one country to another due to variations in consumption behavior and manufacturing practices that are significant across the countries and regions.

The aim of this study is to determine the level of Acrylamide in selected food items especially carbohydrate-rich food items and to examine the effects of reheating food on the Acrylamide levels. In this study, LCMASMS instrument was used after adjusting the analytical method which was used in extraction and isolation of Acrylamide.

\section{MATERIALS AND METHODS}

The study was carried out at the college of pharmacy within the University of Petra in Amman, Jordan between 2016 and 2017 . All reagents, used for the study, were analytical or High-Performance Liquid Chromatography (HPLC) grade. Moreover, the Acetonitrile (CH3CN), n-hexane were supplied by ALPHA Chemicals. Furthermore, Acrylamide and standard Acrylamide were also supplied by ALPHAS Chemicals.

Standard stock solution $(1 \mathrm{mg} / \mathrm{ml})$ was prepared by dissolving $10 \mathrm{mg}$ of Acryl amide in 10ml pure distilled water and stored at 4 Centigrade. All working solutions were prepared daily by serial dilution in double distilled water.

Extraction of Acrylamide from food samples is a rather difficult step due to the fact that Acrylamide may be firmly enclosed and not homogeneously distributed [8][9]. Pure water enables higher Acrylamide recovery compared to methanol. Pure water give's effective extraction of Acrylamide [10-12.] The samples for this study were fried potatoes from five different sources. Moreover, the study also examined the levels of Acrylamide in Pie, cake, biscuits and six different types of breads that is prepared locally. All these samples were obtained from bakeries, fast food chains and supermarkets. Some samples of the potatoes and bread were frozen and then reheated in the oven at $80 \mathrm{c}$ for half an hour, one hour and two hours. 
Sample Preparation:

The samples (20-25g) were disintegrated and homogenized then allowed to swell by soaking in $200 \mathrm{ml}$ of hot double distilled water $(60 \mathrm{c})$ in a $600 \mathrm{ml}$ beaker. Note that more water used for dryer than normal samples. The samples were left for 20minutes and then mixed and homogenized by a mixer for 2 minutes. $40 \mathrm{ml}$ of homogenized sample was transferred to $50 \mathrm{ml}$ screw capped centrifuged for $30 \mathrm{~min}$ at 4000rpm. Furthermore, a $25 \mathrm{ml}$ of the supernatant was transferred to a $100 \mathrm{ml}$ glass centrifuge tube with 20 grams of ammonium sulfate and $25 \mathrm{ml}$ of 2 -butanone were added and shaken for 20 minutes using mechanical shaker. The compound was then transferred to the centrifuge for $15 \mathrm{~min}$ at $4000 \mathrm{rpm} .20 \mathrm{ml}$ of organic layer (butanone) was transferred into a $25 \mathrm{ml}$ test-tube. The organic solvent was evaporated with the aid of steam of pure nitrogen gas which was directed in to the tube and then placed in a water bath at temperatur40c.The dried residue was dissolved in 800ul of acetonitrile (GC grade) and $2 \mathrm{ml}$ of hexane (HPLC GRADE) and mixed for 30second by vortex. The fat in the extracted sample was removed by mixing the acetonitrile layer two times with $2 \mathrm{ml}$ of hexane, and the hexane layer was sucked with glass Pasteur pipette and discarded. The fat free acetonitrile was place in $1.5 \mathrm{ml}$ Class. The clean-up extracted was then analyzed by LCMSMS API13200 (ABSCIX) coupled with HPLC Agilent 1200 series the conditions below

- Instrument LCMSMS API3200 (AB Sciex) coupled with HPLC Agilent 1200 series

- $\quad$ Mobile phase: Acetonitrile: 0.5mM Ammonium chloride (75:25) \%

- Column: Thermo C18 50*2.1

- $\quad$ Calibration Curve Range: $0.1,0.2,0.5,1.0,3.0 \mu \mathrm{g} / \mathrm{mL}(0.1-3.0 \mu \mathrm{g} / \mathrm{mL})$

- Samples Preparation: $50 \mu \mathrm{l}$ (Standard/Sample) in $150 \mu \mathrm{l}$ Diluents' (MeOH: H2)

Table 1: The condition of LGMSMS-(API13200) instrument

\begin{tabular}{|l|l|l|l|l|}
\hline \multirow{3}{*}{ HPLC- Conditions } & Pump Flow Rate & Auto sampler Injection Volume & $\begin{array}{l}\text { Auto sampler } \\
\text { Temp }\end{array}$ & Column Oven Temp \\
\cline { 2 - 5 } & $0.45 \mathrm{~mL} / \mathrm{min}$ & $5 \mu \mathrm{l}$ & Ambient ${ }^{\circ} \mathrm{C}$ & $2{ }^{\circ} \mathrm{C}$ \\
\hline \multirow{2}{*}{$\begin{array}{l}\text { Chromatography- } \\
\text { conditions }\end{array}$} & Total Run Time & $0.8 \mathrm{Min}$ & \\
\cline { 2 - 5 } & Column type & Thermo C18, $(50 * 2.1) \mathrm{mm}, 5 \mu \mathrm{m}$ & \\
\cline { 2 - 5 } & & Acrylamide $=0.32 \mathrm{~min}$ & \\
\hline
\end{tabular}

\section{RESULT AND DISCUSSION}

LCMSMS method was validated to ensure the quality of data. The linearity of the calibration curve was checked by a series of standard solution of Acrylamide ranged from 10 to $300 \mathrm{ug} / \mathrm{l}$ at five different concentrations .

Acrylamide levels were monitored in food samples (Table 2) using High Performance Liquid Chromatography (HPLC). However, the resolution of Acrylamide peak was not clear and sufficient to allow the quantification due to which LCMSMS was used as the condition as mentioned above.

Table 2: Acrylamide level (ug/kg)in selected food items in Jordan

\begin{tabular}{|c|c|c|}
\hline Sub-group /state & Present Study & Published Data \\
\hline potato fried & 247 & $288^{(1)}$ \\
\hline French potato & 259 & $265^{(2)}$ \\
\hline Sliced potato & 262 & $240^{(2)}$ \\
\hline Sliced potato with salt & 172 & Nil \\
\hline Pie with cheese & 134 & Nil \\
\hline Pie with vegetables & 113 & Nil \\
\hline Pie with meat & 98 & Nil \\
\hline Pie with potato & 209 & Nil \\
\hline Pie with sausage & 141 & Nil \\
\hline Pie only & 98 & Nil \\
\hline Pie with zater & 103 & Nil \\
\hline Biscuit & 169 & Nil \\
\hline Sugar biscuit & 209 & Nil \\
\hline Cap cake & 171 & Nil \\
\hline Cookies & 198 & Nil \\
\hline Biscuit with dates & 89 & Nil \\
\hline A-Bread Ishrak & 207 & Nil \\
\hline B-Bread tabon & 279 & Nil \\
\hline C-Bread by machine & 180 & Nil \\
\hline D-Brown bread & 143 & Nil \\
\hline E-Bread with sugar & 201 & Nil \\
\hline F-hamam bread & 294 & Nil \\
\hline White bread & 106 & $85^{(3)}$ \\
\hline
\end{tabular}

N0 information,1 Iveta2014,2 Mottram2002,3 Carere,2006

Table 3: The effects of re heated on the level of Acrylamide $(\mathrm{mg} / \mathrm{kg})$ in fried chips and different types of bread

\begin{tabular}{|c|c|c|c|}
\hline Food items & O time & 30 minutes & 60 minutes \\
\hline Fried chips & 91 & 107 & 119 \\
\hline Fried sliced potato & 88 & 92 & 99 \\
\hline Bread (tabon) & 59 & 78 & 90 \\
\hline Arabic bread & 78 & 101 & 109 \\
\hline Pie with cheese & 69 & 82 & 91 \\
\hline
\end{tabular}

The results were the average of four determinations. It is obvious from the Table (2) that the levels of Acrylamide varied considerably depending on the type of food and even between the same food types. Fried potato, for example, showed the highest level of acrylamide compared to other types of processed potato. It has been reported in the literatures [10-12] that fried potato contains high Acrylamide levels. 
In the same table, the pies show different levels of Acrylamide depending on the type of pie. [8] in 2011 reported the level of Acrylamide in chocolate pie, clustered pies and cheese pies in Jeddah schools. The pie with potato shows high level of Acrylamide when compared with other type of pies due to the fact that potatoes play a significant role in the formation of Acrylamide,Biscuit t, sweet biscuit, cup cake and cookies (table1) show considerable levels of Acrylamide which might be due to the fact that biscuit contains flour ,sugar and fat. When all these exposed to high temperatures used in baking biscuit, all these factors contributed in increased levels of Acrylamide[8] [14].

The Acrylamide levels in different types of bread consumed in Jordan are shown in table 2.It is clear from the table that the levels of Acryl amide are significantly different among different bread varieties i.e., Hama bread showed the highest levels of Acrylamide in addition to tabon and ishrak bread types. This might be due to the type of flour used, ingredients, processing temperature as well as layer thickness. Motaghi, etal reported in 2012 that there was significant levels of Acrylamide present in different types of Iranian bread . The consumption of different bread types is significantly high in Jordan [5].

Table 3 shows the effect of reheated fried pies on Acrylamide levels. Reheating is very common, especially for pies. In this experiment, the effects of diferent reheating periods on Acrylamide levels at temperature of $80^{\circ} \mathrm{c}$ was tested. The increase was significant at 60 minutes of reheating the fried chips and Pie [14] [15][16]This is due to the fact that reheating would increase the reaction among carbohydrates, protein and/or vegetable oils. Such reheating is quite a common scenario in Jordanian food preparation practices.

\section{CONCLUSION}

The present experiments showed that the levels of Acrylamide in different foods especially potato and bread should be monitored and needs to be further investigated to determine the levels of Acrylamide in Jordanian foods. The results indicated that reheating the processed food increases the levels of Acrylamide significantly. Therefore processed food, specifically those items which are high in carbohydrates, should not be reheated for long periods of time.

\section{ACKNOWLEDGEMENTS}

The authors are deeply indebted to University of Petra for its' financial and moral support throughout the study..

\section{REFERENCES}

[1] Iveta, Pugajeva., Laura Zumbure, Aija Melngali.,Vadims Barkeevics.(2014). Determination of Acrylamide Levels in Selected Foods in Latvia and Assessment of the Population, Proceedings of 9th Baltic Conference on Food Science, 11-16.

[2] Carere, A. (2006). Genotoxicity and carcinogenicity of acrylamide: a critical review. Annali-Istituto Superiore Di Sanita, 42(2), 144-149

[3] Svensson, K., Abramsson, L., Becker, W., Glynn, A., Hellenäs, K. E., Lind, Y., \& Rosen, J. (2003). Dietary intake of acrylamide in Sweden. Food and Chemical Toxicology, 41(11), 1581-1586.

[4] WHO Health Organization. (2002). Consulting of health implication of Acrylamide in food, Summary Report of Meeting Held in Geneva, June 25-27, prepared by the sixty-fourth meeting of the Joint FAO/WHO Expert Committee on Food Additives.

[5] Food and Nutrition Profile, Jordan, (2011). www.fao.org/ag/agn/nutrition.

[6] Besaratinia, A., \& Pfeifer, G. P. (2007). A review of mechanisms of acrylamide carcinogenicity. Carcinogenesis, 28(3), 519-528.

[7] Stevenson, K., L.Abramsson, w.,Becker, A,.Glynn., K.E.Hellanas., Y,.Lind ., Rosen.(2003). Dietary intake of Acrylamide in Sweden. Food Chem Toxicol. 41, 1581-1586.

[8] El Tawila, M. M., Al-Ansari, A. M., Alrasheedi, A. A., \& Neamatallah, A. A. (2017). Dietary exposure to acrylamide from cafeteria foods in Jeddah schools and associated risk assessment. Journal of the Science of Food and Agriculture, 97(13), 4494-4500.

[9] Mizukami Y., Kohata K., Yamaguchi Y., (2006). Analysis of acrylamide in green tea by gas chromatography-mass spectrometry. J Agric Food Chem. 2 ,54(19),7370-70377.

[10] Mottram DS, Bronislaw L., WedzichaL. (2002). Food Chemistry of Acrylamide is Formed in the Millard reaction. Nature, Dietary intake of acrylamide in Sweden. Food Chem. Toxicol.3, (41),1581-1586.

[11] Prashant Singh., Pragya Singh., R.Balaji., (2010). Determination of Acrylamide concentration in processed food products using normal phase high performance liquid chromatography. Journal of Biotechnology.9 (47), 8085-8091.

[12] Liu Pengyan,Zhang, Li., Liu LEI,. (2008). Determination of Acrylamide in Potato Chips by High Performance liquid Chromatography Coupled to Diode ArrayDetection.Chemistrymag,2, (41),876-879.

[13 Anese, M., Suman, M., \& Nicoli, M. C. (2010). Acrylamide removal from heated foods. Food Chemistry, $119(2), 791-794$.

[14] Motaghi, M. M., Seyedain, A. M., Honarvar, M., Mehrabani, M., \& Baghizadeh, A. (2012). Determination of acrylamide in selected types of Iranian breads by SPME technique. Journal of Food Bioscience and Technology2,(6)57-64.

[15] Zhang, Y., \& Zhang, Y. (2007). Formation and reduction of acrylamide in Maillard reaction: a review based on the current state of knowledge. Critical Reviews in Food Science and Nutrition, 47(5), 521-542.

[16] Ohara-Takada, A., Matsuura-Endo, C., Chuda, Y., Ono, H., Yada, H., Yoshida, M., ... \& Yamauchi, H. (2005). Change in content of sugars and free amino acids in potato tubers under short-term storage at low temperature and the effect on acrylamide level after frying. Bioscience, biotechnology, and biochemistry, 69(7), 1232-1238. 